\title{
The health status of newly arrived Syrian refugees at the Refugee Health Service, South Australia, 2016
}

Toni Maldari, Natasha Elsley, Razlyn Abdul Rahim

\section{Background and objectives}

Prior to the armed conflict, Syria had undergone an epidemiologic transition in disease burden from communicable to non-communicable diseases. Therefore, it is likely that the health status of Syrian refugees would be different from other refugee cohorts. The aim of this study was to describe the health status of Syrian refugees seen at the Refugee Health Service in South Australia in 2016

\section{Methods}

A cross-sectional study was conducted, and data were collected from medical records. Variables included demographics, infectious diseases, nutritional deficiencies, noncommunicable diseases, mental illness and distress, and physical disabilities.

\section{Results}

The results of the study identified a relatively young cohort with large families. The prevalence of infectious diseases was low $(<10 \%)$, whereas there was a high prevalence of vitamin and micronutrient deficiencies. The rates of chronic disease in adults were high, as were the chronic disease risk factors (overweight/obesity and smoking). In the adult population, $26.9 \%$ reported symptoms such as anxiety, depressed mood and poor sleep.

\section{Discussion}

The findings are consistent with the transitioning burden of communicable to non-communicable disease and chronic diseases in the Syrian population. The study reinforces the importance of comprehensive health screening for new arrival refugees. A validated mental health screening tool was not used, and this requires further research.
THE UnITEd nations High Commissioner for Refugees (UNHCR) has called the Syrian conflict the 'biggest humanitarian and refugee crisis of our time'. More than five million Syrians have crossed international borders and are registered as refugees. The majority have been hosted by neighbouring countries including Turkey, Lebanon and Jordan. ${ }^{1}$ In September 2015, the Australian Government agreed to settle 12,000 Syrian and Iraqi refugees in addition to the existing humanitarian intake (13,750 in 2016).

Refugees arriving under the Commonwealth's Humanitarian Program in Australia have access to healthcare via the public health system and the Medicare Benefits Schedule (MBS). Comprehensive health assessments for refugees are funded under the MBS. ${ }^{2}$ The Australasian Society for Infectious Diseases (ASID) and the Refugee Health Network Australia (RHeaNA) released Recommendations for comprehensive post-arrival health assessment for people from refugee-like backgrounds in 2016 . These recommendations inform what is included in a comprehensive refugee health assessment, with specific recommendations by country of origin and risk. ${ }^{2}$

Refugee Health Service (RHS), formerly known as Migrant Health, is the state-funded specialist health service for refugees in Adelaide, South Australia. The RHS supports new arrival clients with complex health issues. These complexities include large families, chronic disease, disability, trauma and difficulty accessing mainstream services. Clients are referred to RHS by the humanitarian settlement service or by family members, or they may self-refer.

It is likely that the health status and needs of Syrian refugees will differ from other refugee cohorts arriving in Australia. Refugee populations have traditionally come from low-income countries, often spending extended time in refugee camps, and had poor access to health services, even prior to their displacement. More than $90 \%$ of Syrian refugees have settled in the host country community and only a small proportion in refugee camps. ${ }^{1}$ Prior to the Syrian conflict, the country was undergoing an epidemiologic transition, with the bulk of the nation's disease burden moving from infectious diseases to chronic and non-communicable diseases (NCD). ${ }^{4}$

While the complete disruption of the health system in Syria has resulted in several outbreaks including polio, ${ }^{5}$ measles ${ }^{5,6}$ and leishmaniasis, ${ }^{7}$ the major issue facing refugees living in neighbouring countries is the discontinuation of treatment for their chronic diseases. ${ }^{8}$ Healthcare in a humanitarian crisis is generally poorly equipped to deal with chronic disease management. ${ }^{9,10}$ NCDs are prevalent in Syrian refugees living in Lebanon, Turkey and Jordan, and access to healthcare was reported as a major issue for this population..$^{8,11,12}$ It is likely that the Syrian refugee population in Australia will have a high prevalence of NCDs, and these conditions may have been affected by poor access to healthcare.

While acute malnutrition is a growing issue in many areas of Syria itself, especially areas under siege, ${ }^{4,6}$ it was not found to be an issue for Syrian refugees living in neighbouring countries. ${ }^{14} \mathrm{~A}$ large study in Jordan found that Syrian refugee children, on average, were slightly overweight. However, anaemia was still prevalent both in the camps and in refugees settled in the community; 
$>40 \%$ of women and children in Zaatari camp and almost $30 \%$ of women and children living in the community were anaemic. This has implications for the screening of anaemia, iron and vitamin B12 in Syrian refugees arriving in Australia.

There is little evidence to guide recommendations regarding infectious disease screening in Syrian refugees. The prevalence of hepatitis $\mathrm{C}$ in Middle Eastern countries is reported at approximately 1\%. ${ }^{15}$ Evidence suggests chronic hepatitis $\mathrm{B}$ rates are approximately $5 \%$ in Syria. ${ }^{16,17}$ Tuberculosis (TB) prevalence in Syria is reported to be 19 per 100,000, which is lower than many European countries and the European average. ${ }^{18}$

There is scant data available regarding parasite prevalence, including strongyloides, schistosomiasis and soil-transmitted helminths in Syria. ${ }^{21}$ Cutaneous leishmaniasis is reported to affect the Syrian refugee population in parts of Syria and is spreading to Lebanon. ${ }^{7,22}$ There is little data regarding the prevalence of sexually transmitted infections in the Middle East or in Syrian refugee populations.

While outside the purpose of this study, it is important to consider mental health issues when caring for people of refugee backgrounds. The World Health Organization predicts that up to $20 \%$ of people will develop mild-to-moderate mental health disorders in a humanitarian emergency setting. A larger proportion will demonstrate signs and symptoms of distress and normal reactions to high stress without having a diagnosable disorder. ${ }^{23}$

Many Syrian refugees report experiencing conflict-related violence and high levels of stress related to displacement such as poverty, food insecurity, fears for safety, discrimination, loss of family, isolation and uncertainty. ${ }^{24}$ The most common mental health disorders reported in the Syrian refugee population are depression, prolonged grief reactions, post-traumatic stress disorder and anxiety disorders. ${ }^{25}$

The objective of this study was to describe the health status of Syrian refugees seen at RHS in terms of demographics, prevalence of infectious diseases, nutritional deficiencies, NCDs and non-specific complaints, mental illness, distress and physical disabilities. Findings will help to inform future screening of Syrian refugees, screening guidelines and health service provision and planning.

\section{Methods \\ Study design}

A cross-sectional study was conducted based on a retrospective medical records audit.

\section{Setting}

RHS is the state-funded specialist refugee health service in Adelaide, South Australia. The study period was between 1 January 2016 and 31 December 2016.

\section{Participants}

Study participants were all new arrival Syrian adults and children who attended RHS within the study period. Participants were referred to RHS by the state settlement service provider. All patients were seen with a qualified interpreter.

\section{Data collected}

Data were collected from electronic medical records software (Medical Director) and hard copy records and subsequently populated into a Microsoft (MS) Excel spreadsheet. A list of collected variables is included in Table 1.

\section{Data analysis}

Data were analysed for descriptive statistics, examining the mean and range for continuous variables, and frequency of cases with percentages for categorical variables. Cross-tabulation was used to determine frequencies within subgroups. Data analysis was performed using STATA 15 and MS Excel.

This study was approved by the South Australian Health Human Research Ethics Committee (reference number HREC/16/ $\mathrm{SAH} / 119)$.

\section{Results}

A total of 932 new arrivals registered at RHS in 2016; of these, 455 were Syrian. RHS saw approximately $60 \%$ of the Syrians who arrived in South Australia in 2016 (Department of Social Services, Australian Government, email communication, 17 July 2018). All except one individual underwent the new arrival comprehensive health assessment. The health assessment was based on ASID/RHeaNA recommendations for comprehensive health assessment for people from refugee-like backgrounds. The screening pathology tests included full blood count, electrolytes, liver function, hepatitis B serology, hepatitis C antibody, human immunodeficiency virus (for people aged $>15$ years), schistosomiasis serology, strongyloides serology, iron studies, vitamin D and vitamin B12. All children aged $<18$ years had stool testing for parasites; stool testing was done for Helicobacter pylori if symptomatic. Adults with gastrointestinal symptoms (pain, diarrhoea) also had stool testing for parasites. While testing for electrolytes and liver function is not included in the ASID/RHeaNA recommendations, calcium and alkaline phosphatase levels assist with interpretation and management of vitamin $\mathrm{D}$ deficiency.

\section{Demographic characteristics}

Participants ranged in age from $<1$ year to 81 years, with a mean age of 20.2 years. The population predominantly comprised families with between six and 15 members. Seventy-four Syrian families attended RHS in 2016. More than half were in Lebanon prior to resettlement (Table 2).

\section{Infectious diseases}

Table 3 shows the prevalence of infectious diseases. Immunity to hepatitis B from vaccination was found in $61.6 \%$ of children and $13.4 \%$ of adults.

\section{Micronutrient and vitamin deficiencies}

Table 2 shows the relatively high prevalence of vitamin D, vitamin B12 and iron deficiency. Of the population of adult women, $64.5 \%$ were iron deficient $(n=48)$.

\section{Chronic disease}

In the adults, $39.7 \%$ of males and $26.9 \%$ of females had a chronic disease, including diabetes, hypertension, asthma, ischaemic heart disease and chronic obstructive 


\section{Table 1. Refugee Health Service screening tests and criteria}

\begin{tabular}{|c|c|c|}
\hline Variable & Test & Refugee Health Service screening criteria \\
\hline $\begin{array}{l}\text { Schistosomiasis - P/N } \\
\text { Strongyloides - P/N } \\
\text { Giardia lamblia } \\
\text { Dientamoeba fragilis } \\
\text { Helicobacter pylori P/N } \\
\text { Human immunodeficiency virus - P/N } \\
\text { Hepatitis C - P/N } \\
\text { Hepatitis B } \\
\text { Chronic hepatitis B } \\
\text { Immune (vaccinated) } \\
\text { Non immune } \\
\text { Past infection } \\
\text { Core antibody positive }\end{array}$ & $\begin{array}{l}\text { Serology } \\
\text { Serology } \\
\text { Stool MCS, OCP, NAAT } \\
\text { Stool MCS, OCP, NAAT } \\
\text { Stool antigen } \\
\text { Serology } \\
\text { Serology } \\
\text { Hepatitis B surface antigen, } \\
\text { hepatitis B surface antibody, } \\
\text { hepatitis B core antibody }\end{array}$ & $\begin{array}{l}\text { All } \\
\text { All } \\
\text { Age }<18 \text { years or abdominal symptoms } \\
\text { Age }<18 \text { years or abdominal symptoms } \\
\text { Abdominal pain } \\
\text { Age }>15 \text { years } \\
\text { All } \\
\text { All }\end{array}$ \\
\hline $\begin{array}{l}\text { Vitamin } D \\
\text { Normal } \geq 50 \mathrm{nmol} / \mathrm{L} \\
\text { Mild deficiency } 30-49 \mathrm{nmol} / \mathrm{L} \\
\text { Moderate/severe deficiency }<30 \mathrm{nmol} / \mathrm{L}\end{array}$ & Serum level nmol/L & All \\
\hline $\begin{array}{l}\text { Vitamin B12 (active) } \\
\text { Normal } \geq 31 \mathrm{pmol} / \mathrm{L} \\
\text { Deficiency } 0-30 \mathrm{pmol} / \mathrm{L}\end{array}$ & $\begin{array}{l}\text { Serum level } \\
\text { If total vitamin } B 12<260 \mathrm{pmol} / \mathrm{L} \text {, } \\
\text { then active vitamin } \mathrm{B} 12 \text { reported }\end{array}$ & All \\
\hline $\begin{array}{l}\text { Iron studies } \\
\text { Deficiency in adults ferritin }<30 \mathrm{uG} / \mathrm{L} \\
\text { Deficiency in children ferritin }<20 \mathrm{uG} / \mathrm{L}\end{array}$ & Serum ferritin & All \\
\hline
\end{tabular}

\begin{tabular}{ll}
\hline Chronic disease & Patient/clinician reported \\
Diabetes & \\
Hypertension & \\
Cardiovascular disease & \\
Chronic respiratory illness (chronic obstructive & \\
pulmonary disease or asthma) &
\end{tabular}

\begin{tabular}{lll}
\hline Mental health & Patient/clinician reported & Age $>18$ years
\end{tabular}

Pre-existing diagnosed mental health disorder

Referral to counselling/mental health service

General symptoms

Patient reported

Chronic headaches

Gastrointestinal symptoms

Musculoskeletal symptoms

\begin{tabular}{lll}
\hline Smoking status & Patient reported & Age $>18$ years \\
\hline Body mass index & Clinician calculated & Age $>18$ years \\
\hline Physical disability & Patient/clinician reported & All \\
Congenital/developmental & & \\
Conflict-related injury & & \\
Other acquired & & \\
\hline
\end{tabular}

MCS, microscopy, culture and sensitivity; OCP, ova, cysts and parasites; N/A, not applicable; NAAT, nucleic acid amplification test; P/N, positive/negative 
pulmonary disease (Table 2). Results are based on the patient's self-reported history, overseas medical documentation, prescribed medication and assessment in Australia.

Smoking and obesity are two of the risk factors for chronic disease. Forty (43.5\%) Syrian men were smokers; 19 of these were reformed smokers. The prevalence of smoking was lower in women (Figure 1). The body mass index of Syrian adults showed $129(72.1 \%)$ people were overweight or obese (Figure 2).

\section{Mental health and disability}

Of the 178 adults assessed during the initial health assessment, 48 individuals (26.9\%) reported symptoms such as

Table 2. Demographic characteristics of Syrian new arrival refugees at the Refugee Health Service, 2016

\begin{tabular}{lcc}
\hline & n & $\%$ \\
\hline Sex & 223 & 49 \\
\hline Male & 232 & 51 \\
\hline Age (years) & & \\
\hline $0-9$ & 145 & 31.9 \\
\hline $10-17$ & 123 & 27.1 \\
\hline $18-29$ & 49 & 10.8 \\
\hline $30-39$ & 66 & 14.5 \\
\hline $40-49$ & 44 & 9.7 \\
\hline $50-59$ & 17 & 3.7 \\
\hline$>60$ & 10 & 2.2 \\
\hline Not reported & 1 & 0.2 \\
\hline Children (0-17 years) & 268 & 58.9 \\
\hline Adults ( $\geq 18$ years) & 186 & 41.1 \\
\hline
\end{tabular}

Transit country

\begin{tabular}{lrr}
\hline Jordan & 157 & 34.5 \\
\hline Lebanon & 254 & 55.8 \\
\hline Others & 37 & 8.1 \\
\hline Not reported & 7 & 1.5 \\
\hline Total & $\mathbf{4 5 5}$ & $\mathbf{1 0 0}$
\end{tabular}

anxiety, depressed mood and poor sleep. Of these, 38 individuals were referred for further assessment. Other commonly reported symptoms in adults included musculoskeletal pain (36.7\%) and gastrointestinal (29.1\%) complaints (abdominal pain, constipation, diarrhoea).

Seven children and nine adults (3.5\%) had some form of disability secondary to previous injury or developmental abnormalities. All required specialist and/ or allied health assessment.

\section{Discussion}

The findings of this study illustrate several key characteristics of the demographic and health profile of the new arrival
Syrian refugees who attended RHS in 2016. The cohort was relatively young and predominantly consisted of large families. This reflects the population structure in Syria, where more than half are aged $<24$ years, and the Australian government's commitment to prioritising vulnerable groups such as children, women and families for resettlement. ${ }^{26,27}$

Selected parasites and helminth infestations were detected in $<10 \%$ of the cohort; however, direct comparisons cannot be made with existing data in the literature because of the variation in study populations. Schistosomiasis was treated on the basis of positive serology. Given the reasonably high sensitivity $(87 \%)$ of the serological test, we are confident that most

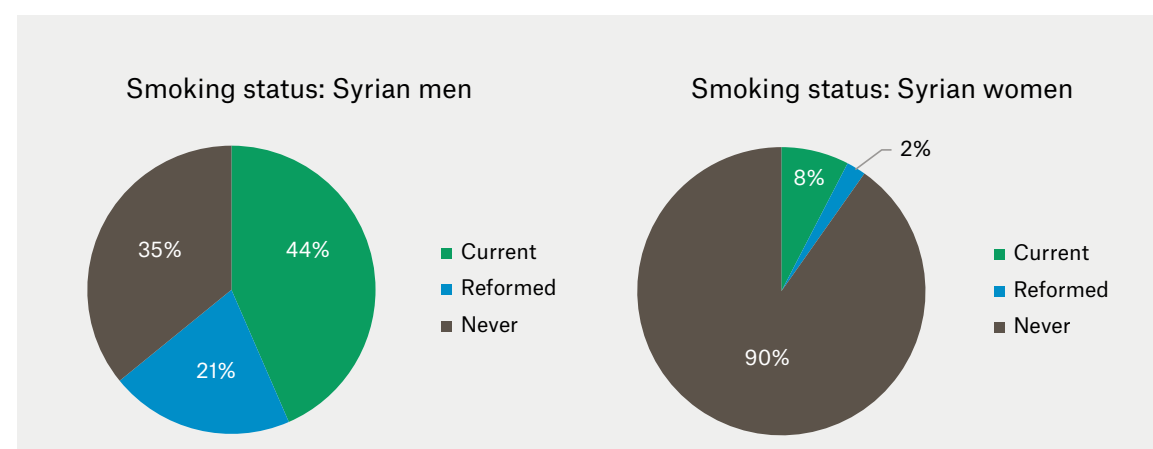

Figure 1. Smoking status of Syrian adults at the Refugee Health Service, 2016

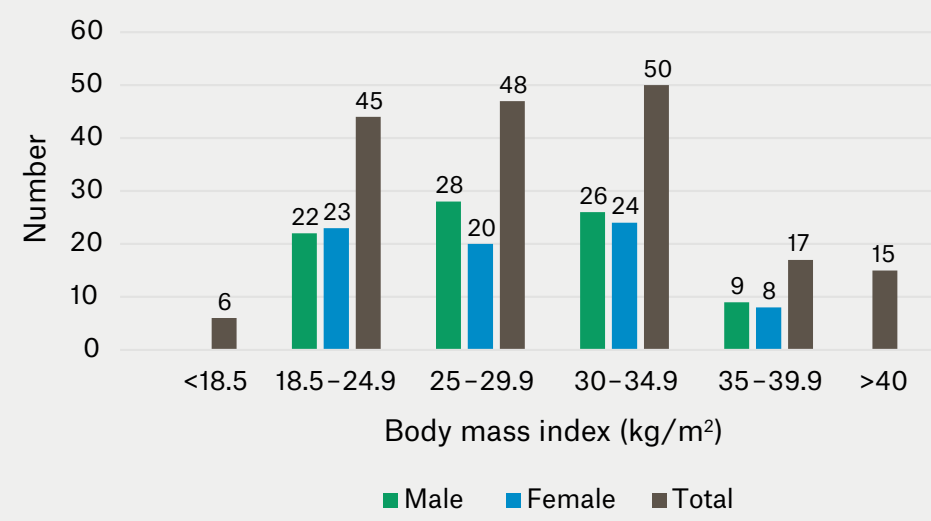

Figure 2. Body mass index of Syrian adults at the Refugee Health Service, 2016 *If $n<5$, individual frequencies are not reported. 
Table 3. Results of new arrival screening at the Refugee Health Service, 2016

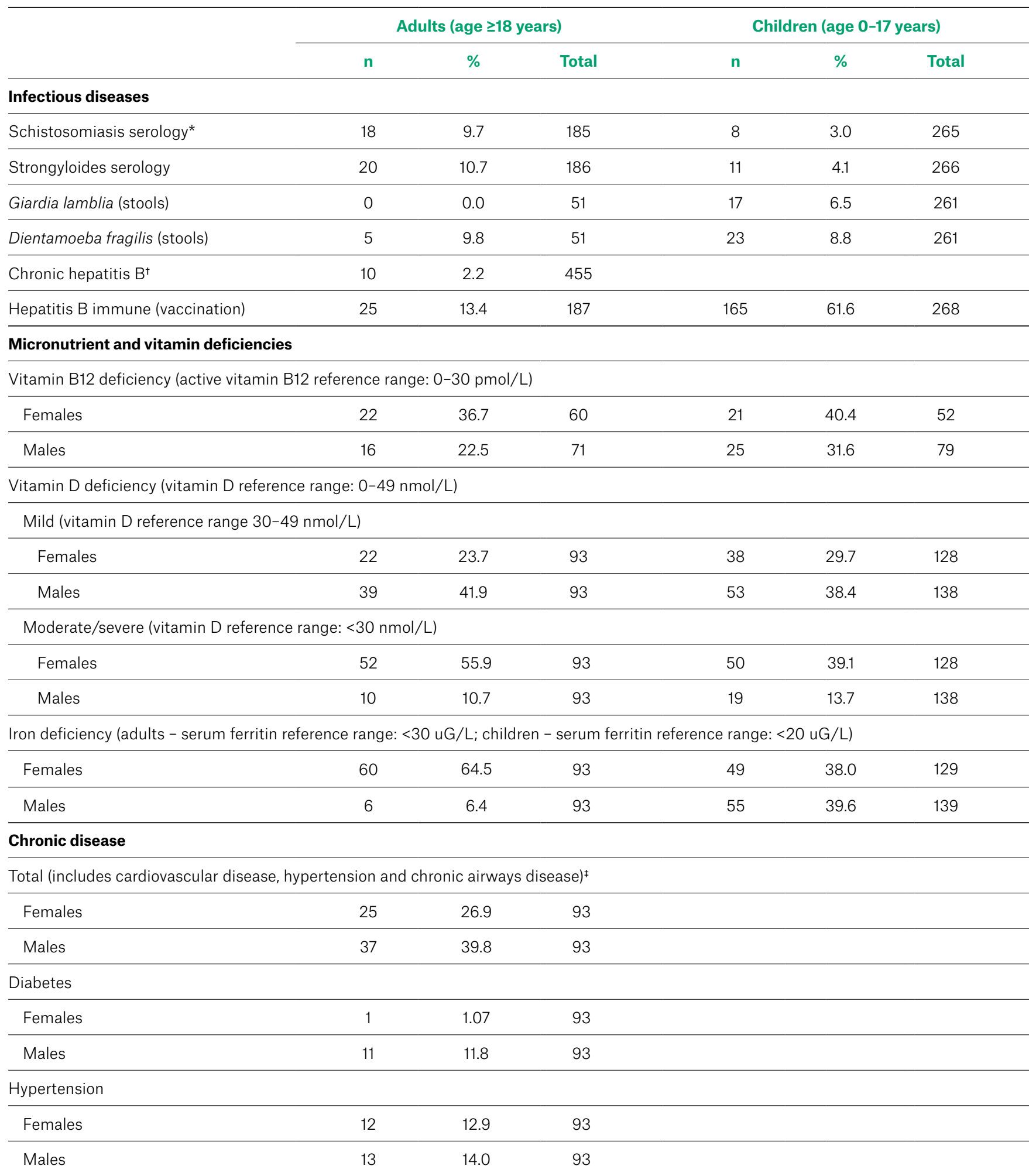

*Nova Lisa enzyme immunoassay; specificity $>97 \%$, sensitivity $87 \%$

${ }^{\dagger}$ Chronic hepatitis $B$ data are reported for total population (combined adults and children) because of very small numbers within each subgroup. ¥Measured in adults only 
cases were correctly detected, and the very high specificity (>97\%) indicates that very few cases were incorrectly diagnosed and treated. Findings for strongyloides were similar. Schistosomiasis and strongyloides were treated as per ASID/ RHeaNA guidelines. These findings reinforce the continued need to test for these easily treatable diseases with potentially significant medical sequelae. The prevalence of chronic hepatitis B in this study cohort was half that previously reported for Syria. ${ }^{16,17}$

Significant proportions of the study cohort had vitamin and micronutrient deficiencies, which is likely consistent with previous studies identifying high rates of anaemia. Many people stated that food security was an issue during the period of displacement. Vitamin D deficiency is well documented in refugees; as expected, high rates of vitamin D deficiency were found in this cohort.

The study findings support previous reports of the burden of chronic disease in the Syrian population. Chronic disease risk factors such as smoking and overweight or obese body habitus were prevalent in the study cohort, in addition to conditions such as diabetes and hypertension. The mean age of adults with any form of chronic disease was comparable to the general Australian population at 45.6 years. ${ }^{28}$ Smoking was more prevalent in men in our study cohort when compared with country statistics for Syria - 43\%, compared with $21.18 \%$; whereas the proportion of female smokers was similar to that in Syria - 8\%, compared with $8.5 \% .{ }^{29}$ There were reports of interruption to medication supply and limited access to chronic disease follow-up prior to resettlement.

Screening for latent TB infection is conducted by the Chest Clinic in South Australia, thus not reported in this study. It should be noted that active TB is excluded by pre-departure screening, and children aged 2-10 years undergo latent TB testing prior to departure.

It is likely that the findings underestimated the burden of mental health issues. Anecdotally, many individuals have presented with mental health symptoms in the 3-12 months post-arrival. A combination of post-settlement stressors have an impact on presentations, including job-seeking obligations and attending English-language classes while having to fulfil family and carer responsibilities. Additionally, the trauma of escaping an acute war zone, separation and concern regarding safety of family and friends remaining in Syria, continued exposure to the ongoing Syrian crisis through the media and social media, and communication with relatives all contribute to significant mental health burden. These factors also affect children and adolescents; however, this was not within the scope of this study and warrants a separate study.

In terms of disability management, despite the small numbers, there were challenges in obtaining services and support. These were more promptly accessed for children as referral and diagnostic pathways for services catering to adults with disabilities are less clear. The phased rollout of the National Disability Insurance Scheme also contributed to difficulty accessing services at the time of the study.

This study had several limitations. Data collected was based on the initial appointment and up to three months post-arrival. Symptoms of mental distress were noted; however, a validated mental health screening tool was not used. This, along with the latency of these presentations, may not have accurately captured data on mental health issues or may have resulted in missed presentations.

Study findings are not strongly generalisable to the Syrian population given that the settlement service provider allocates those with more complex health and social needs to receive primary healthcare at RHS. Nevertheless, the large sample size and few missing data for each variable examined produced robust estimations of prevalence of selected health conditions, adding to existing knowledge on the health profile of this population.

\section{Conclusion and implications for general practice}

Study findings are consistent with the transitioning burden of disease from communicable to non-communicable and chronic diseases in the Syrian population.

The results highlight the importance of comprehensive health screening for new arrivals of refugee background in line with ASID/RHeaNA recommendations. It is recommended that health screening includes screening for infectious disease, nutritional and vitamin deficiencies and chronic disease. Further studies are needed to look at mental health screening in new arrival refugees. It is recommended that health professionals are aware of the evolving nature of psychological distress, which often results from a combination of the trauma of escaping an acute conflict area and the stressors unique to resettlement. This warrants ongoing monitoring and early identification to allow for prompt intervention.

\section{Authors}

Toni Maldari BMBS, FRACGP, Senior Medical Officer, Refugee Health Service, Adelaide, SA. Antonietta. maldari@sa.gov.au

Natasha Elsley MBBS, FRACGP, MPHTM, DCH, General Practitioner, Refugee Health Service, Adelaide, SA

Razlyn Abdul Rahim MBBS, MPH, FAFPHM, PhD candidate, School of Public Health, Faculty of Health and Medical Sciences, University of Adelaide, Adelaide, SA; Support Public Health Medical Officer, Aboriginal Health Council of South Australia, Adelaide, SA

Competing interests: None.

Funding: None.

Provenance and peer review: Not commissioned, externally peer reviewed.

\section{Acknowledgements}

We would like to acknowledge the staff and clients of the Refugee Health Service, and Ms Jan Williams, Dr Mitchell Smith and Dr Aesen Thambiran for their comments on an earlier draft of this manuscript.

\section{References}

1. United Nations High Commissioner for Refugees. Syrian regional refugee response. Geneva: UNHCR, 2019. Available at http://data.unhcr.org/ syrianrefugees/regional.php\#_ga=1.55542766.410 804990.1469754672 [Accessed 16 April 2019].

2. Chaves NJ, Paxton G, Biggs BA, et al. Recommendations for comprehensive post-arrival health assessment for people from refugee-like backgrounds. Surrey Hills, NSW: Australasian Society for Infectious Diseases, 2016. Available at www.asid.net.au/documents/item/1225 [Accessed 16 April 2019].

3. Dewachi O, Skelton M, Nguyen V-K, et al. Changing therapeutic geographies of the Iraqi and Syrian wars. Lancet 2014;383(9915):449-57. doi: 10.1016/S0140-6736(13)62299-0.

4. Taleb ZB, Bahelah R, Fouad FM, Coutts A, Wilcox M, Maziak W. Syria: Health in a country undergoing tragic transition. Int J Public Health 2015;60 Suppl 1:63-72. doi: 10.1007/s00038014-0586-2. 
5. Ozaras R, Leblebicioglu $H$, Sunbul M, et al. The Syrian conflict and infectious diseases. Expert Rev Anti Infect Ther 2016;14(6):547-55. doi: 10.1080/14787210.2016.1177457.

6. Meiqari L, Hoetjes M, Baxter L, Lenglet A. Impact of war on child health in northern Syria: The experience of Médecins Sans Frontières. Eur J Pediatr 2018;177(3):371-80. doi: 10.1007/s00431017-3057-y.

7. Sharara SL, Kanj SS. War and infectious diseases: Challenges of the Syrian civil war. PLoS Pathog 2014;10(11):e1004438. doi: 10.1371/journal. ppat.1004438.

8. El-Khatib Z, Scales D, Vearey J, Forsberg BC. Syrian refugees, between rocky crisis in Syria and hard inaccessibility to healthcare services in Lebanon and Jordan. Conflict Health 2013;7(1):18. doi: 10.1186/1752-1505-7-18.

9. Ruby A, Knight A, Perel P, Blanchet K, Roberts B. The effectiveness of interventions for noncommunicable diseases in humanitarian crises: A systematic review. PloS One 2015;10(9):e0138303. doi: 10.1371/journal.pone.0138303.

10. Rabkin M, Fouad FM, El-Sadr WM. Addressing chronic diseases in protracted emergencies: Lessons from HIV for a new health imperative. Glob Public Health 2018;13(2):227-33. doi: 10.1080/17441692.2016.1176226.

11. Holmes D. Chronic disease care crisis for Lebanon's Syrian refugees. Lancet Diabetes Endocrinol 2015;3(2):102. doi: 10.1016/S22138587(14)70196-2.

12. Doocy S, Lyles E, Roberton T, Akhu-Zaheya L, Oweis A, Burnham G. Prevalence and care-seeking for chronic diseases among Syrian refugees in Jordan. BMC Public Health 2015;15(1):1097. doi: 10.1186/s12889-015-2429-3.

13. Sethi S, Jonsson R, Skaff R, Tyler F. Communitybased noncommunicable disease care for Syrian refugees in Lebanon. Glob Health Sci Pract 2017;5(3):1-12. doi: 10.9745/GHSP-D-17-00043.

14. Bilukha OO, Jayasekaran D, Burton A, et al. Nutritional status of women and child refugees from Syria-Jordan, April-May 2014. MMWR Morb Mortal Wkly Rep 2014;63(29):638-39.

15. Gower E, Estes C, Blach S, Razavi-Shearer K, Razavi H. Global epidemiology and genotype distribution of the hepatitis $\mathrm{C}$ virus infection. J Hepatol 2014;61 Suppl 1:S45-57. doi: 10.1016/j. jhep.2014.07.027.

16. Specialist panel on chronic hepatitis $B$ in the Middle East. A review of chronic hepatitis $B$ epidemiology and management issues in selected countries in the Middle East. J Viral Hepat 2012;19(1):9-22. doi: 10.1111/j.13652893.2011.01511.x.

17. Pottie K, Greenaway C, Hassan G, Hui C, Kirmayer LJ. Caring for a newly arrived Syrian refugee family. CMAJ 2016;188(3):207-11. doi: 10.1503/cmaj.151422.

18. Khan MS, Osei-Kofi A, Omar A, et al. Pathogens, prejudice, and politics: The role of the global health community in the European refugee crisis. Lancet Infect Dis 2016;16(8):e173-77. doi: 10.1016/ S1473-3099(16)30134-7.

19. Mockenhaupt FP, Barbre KA, Jensenius $M$, et al. Profile of illness in Syrian refugees: A GeoSentinel analysis, 2013 to 2015. Euro Surveill 2016;21(10):30160. doi: 10.2807/1560-7917. ES.2016.21.10.30160.

20. Almerie MQ, Azzouz MS, Abdessamad MA, et al. Prevalence and risk factors for giardiasis among primary school children in Damascus, Syria. Saudi Med J 2008;29(2):234-40.
21. Hanieh S, Ryan N, Biggs B-A. Assessing enteric helminths in refugees, asylum seekers and new migrants. Microbiol Aust 2016;37(1):15-19. doi: 10.1071/MA16006.

22. Al-Salem WS, Pigott DM, Subramaniam K, et al. Cutaneous leishmaniasis and conflict in Syria. Emerg Infect Dis 2016;22(5):931-33. doi: 10.3201/ eid2205.160042.

23. Hassan G, Kirmayer L, Mekki-Berrada A, et al. Culture, context and the mental health and psychosocial wellbeing of Syrians: A review for mental health and psychosocial support staff working with Syrians affected by armed conflict. Geneva: UNHCR, 2015. Available at www.unhcr.org/en-my/55f6b90f9.pdf [Accessed 16 April 2019].

24. Sijbrandij M, Acarturk C, Bird M, et al. Strengthening mental health care systems for Syrian refugees in Europe and the Middle East: Integrating scalable psychological interventions in eight countries. Eur J Psychotraumatol 2017;8 Suppl 2:1388102. doi: 10.1080/20008198.2017.1388102.

25. Quosh C, Eloul L, Ajlani R. Mental health of refugees and displaced persons in Syria and surrounding countries: A systematic review. Intervention 2013;11(3):276-94. doi: 10.1097/ WTF.0000000000000013.

26. Central Intelligence Agency. The World Factbook, Middle East, Syria. Washington, DC: ClA, 2019. Available at https://www.cia.gov/library/ publications/resources/the-world-factbook/geos/ sy.html [Accessed 13 June 2019].

27. Department of Home Affairs. Australia's response to the Syrian and Iraqi humanitarian crisis. Canberra: DOHA, [date unknown]. Available at https://archive.homeaffairs.gov.au/trav/refu/ response-syrian-humanitarian-crisis [Accessed 16 April 2019].

28. Australian Institute of Health and Welfare. Australia's Health 2016. Canberra: AlHW, 2016. Available at www.aihw.gov.au/ getmedia/9844cefb-7745-4dd8-9ee2f4d1c3d6a727/19787-AH16.pdf.aspx?inline=true [Accessed 16 April 2019].

29. Drope J, Schluger N, Cahn Z, et al. The tobacco atlas: Syria. Atlanta: American Cancer Society and Vital Strategies, 2019. Available at https:// tobaccoatlas.org/country/syria/ [Accessed 16 April 2019]. 